\title{
Efficacy Study of Using Cognitive Information Process Model in College Counseling
}

\author{
Jiyang Wu \\ Suzhou Yiiway Education Technology Co., Ltd., Suzhou, China \\ Email:michael.wood@yiiway.com
}

How to cite this paper: Wu, J. Y. (2018) Efficacy Study of Using Cognitive Information Process Model in College Counseling. Psychology, 9, 2984-2995.

https://doi.org/10.4236/psych.2018.915173

Received: November 20, 2018

Accepted: December 22, 2018

Published: December 25, 2018

Copyright $\odot 2018$ by author and Scientific Research Publishing Inc. This work is licensed under the Creative Commons Attribution International License (CC BY 4.0).

http://creativecommons.org/licenses/by/4.0/

\begin{abstract}
Career indecision and career indecisiveness are the two mostly cited phrases concerning the decision-making in campus. The author will address the question of "what is the efficacy of Cognitive Information Process (CIP; Peterson, Sampson, Reardon, \& Lenz, 1996; Peterson, Sampson Jr., Lenz, \& Reardon, 2002; Sampson Jr., Reardon, Peterson, \& Lenz, 2004) approach on the treatment of college students who are experiencing career indecision and career indecisiveness" by conducting a literature review of the latest research findings.
\end{abstract}

\section{Keywords}

CIP, Career Thoughts Inventory, CTI, Cognitive Information Process,

College Counseling, Career Indecision, Career Indecisiveness

\section{Introduction}

College students face two important decision-making milestones during the 4 -year time span. First of all, declaration of a field of major will subsequently lead to intensive resources being put in the chosen area and will mostly direct the occupational pursuit. Secondly, entry into the world of work requires tremendous physical and psychological energy. Many would encounter difficulties and hesitations during the decision-making points. For example, Beggs, Bantham, and Taylor (2008) argued that research has shown that a decision pertaining to choosing a college major is most frequently identified as a life regret for Americans.

\subsection{Career Indecision and Career Indecisiveness}

Career indecision and career indecisiveness are the two mostly cited phrases concerning the decision-making in campus; however, the two constructs are so different that warrant a close look. Career indecision "refers to the difficulties 
preventing individuals from making a career decision" (Gati, Gadassi, Saka, Hadadi, Ansenberg, Friedmann, \& Asulin-Peretz, 2011: p. 3). Career indecisiveness refers to a state when clients feel stuck in the day-to-day formalities of their lives, which mainly stem from the consequences of emotional and personality related characteristics (Gati et al., 2011). The former deals mostly with the knowledge, experiences, and skills in making a quality decision concerning major selection and occupation pursuit whereas the latter draws attention to the dysfunctional and negative thoughts pertaining to the decision-making process.

In this project, the author will address the question of "what is the efficacy of Cognitive Information Process (CIP; Peterson, Sampson, Reardon, \& Lenz, 1996; Peterson, Sampson Jr., Lenz, \& Reardon, 2002; Sampson Jr., Reardon, Peterson, \& Lenz, 2004) approach on the treatment of college students who are experiencing career indecision and career indecisiveness" by conducting a literature review of the latest research findings.

\subsection{The Cognitive Information Processing Model}

The CIP approach incorporates cognitive operations to the traditional Parsonian model for making career choices (Niles \& Bowlsbey, 2009). It builds upon the traditional trait-and-factor theory of career decision-making and further extends its emphasis to the interactions between cognitive and affective processes. The CIP model posits that the career decision-making is more than a linear solution-focused process; it not only sees the self-understanding and exploration of the occupational resources as the foundations to the decision-making process, but also stresses the importance of self-awareness and self-regulatory cognitive operations.

There are three basic domains as delineated in the Pyramid of Information Processing: the Knowledge Domain, the Decision-Making Domain, and the Executive Processing Domain (Figure 1). In the bottom of the pyramid, the knowledge domain speaks about the personal interests, values, skills, and personality; and the occupation knowledge refers to the understandings of general job-market, specific occupations, and education/skills needed for the specific occupations.

Built on the knowledge domains, a generic information-processing decision-making skill is presented to aid the career decision-making. The so-called CASVE cycle (communication, analysis, synthesis, value, and execution) is a sequential decision-making procedure (Capuzzi \& Stauffer, 2006). Clients can return to the communication stage to evaluate the outcome of the career decision-making, and any discrepancies in the cognitive, behavioral, affective, and physiological state can trigger the recycle of the CASVE process (Niles \& Bowlsbey, 2009).

The third domain of the CIP approach is the executive processing domain, which involves metacognitive skills (Meichenbaum, 1977; as cited in Niles \& Bowlsbey, 2009). Metacognitive skill refers to the cognition to the cognitive operations, which includes the conscious and unconscious manipulation of the 


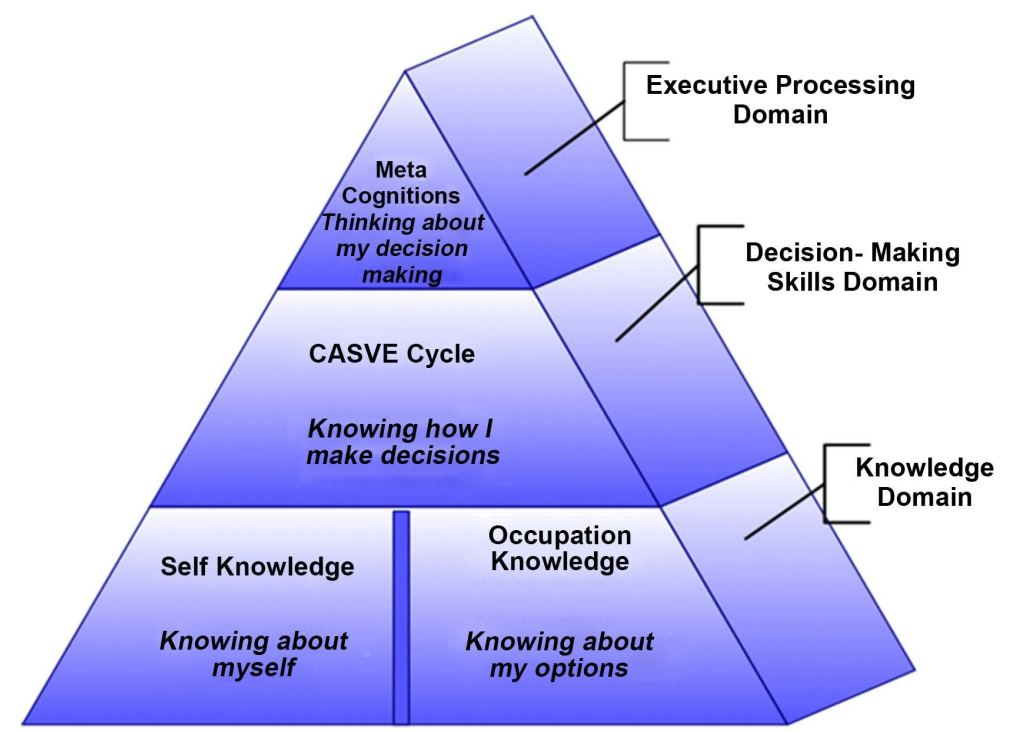

Figure 1. Pyramid of information processing model. Adapted from: Sampson Jr., Peterson, Lenz, \& Reardon (1992). A cognitive approach to career services: Translating concepts into practice. Career Development Quarterly, 41, 67-74. Copyright (C) National Career Development Association.

information. Peterson et al. (1996) argued that the conscious control and monitoring of the cognitive operation are essential to a well-informed career decision-making, and the goal of career counseling is to enhance individual's information processing skill by looking into the self-talk, self-awareness, and automatic thoughts concerning the career decision-making. The following sections will present a summary of research findings that incorporate CIP approach to address college students' career indecision and career indecisiveness.

\section{Applying CIP Approach in Rational Career Decision-Making}

Career decision-making is a key theme throughout the life course. Career decision-making is influenced by many factors such as level of self-knowledge and occupational knowledge, interactions with family members, religious affiliations, and perceived gender roles. For example, Beggs, Bantham and Taylor (2008) conducted a mixed methods study to identify the foundations of the psychological process by which the college students select their academic majors. In the qualitative part of the research, the researchers found that fit and interest in the subject, job characteristics, functional/utilitarian issues, and personal sources of information are the most interested topics in major selection whereas comprehensive information searches are the least interested topics. In the subsequent quantitative part of the research, the researchers sampled 4792 college students to understand their view of the importance of those themes emerged from the qualitative research. The result showed that the order of interests in terms of importance in major selection is: match with interests, course/major attributes, job characteristics, financial considerations, psycho/social benefits, and information 
search. The final result demonstrated that self-knowledge (interest) and occupational knowledge (job characteristics) are the key ingredients in career decision-making. Another example relates to Whitmarsh, Brown, Cooper, Hawkins-Rodgers, and Wentworth's (2007) research on professional women's career patterns. The purpose of this qualitative research was to examine the similarities and differences in the career paths of women in female-dominated careers and women who made career choices that were gender neutral. The result revealed that career decision-making is one of the six themes emerged. Furthermore, the researchers found that the women who chose female-dominated careers more often made career decisions earlier and were much influenced by mothers and other female relatives. In contrast, the women who chose gender-neutral careers tended to make career decisions later and were influenced by more versatile people such as peers, professors, career mentors, and supervisors. The findings from the literature review suggest that career decision-making is a complex process that involves many factors, which warrants a thoughtful and systematic approach.

\subsection{Application of CIP Approach in Career Decision-Making}

Rational career decision-making pertains mostly to clients undergoing career indecision, who generally lack knowledge, experiences, and skills in making a quality decision. However, clients labeled as undecided (career indecision) are normally motivated to make a change in career path but are not sure what steps to take, and career indecision happens when clients feel unsure what to do in order to make a career change or transition. They normally are lack of needed experience and knowledge to make effective and sound career decisions.

Considering that CIP approach is rooted in Parsonian model of trait-and-factor and incorporates the recent development in the cognitive area (Niles \& Bowlsbey, 2009), it can help clients with career indecision in the following three steps. First of all, counselor can help clients exploring self-knowledge by applying personality and interest assessment. The enhanced self-knowledge builds the foundation for career decision-making. Secondly, counselor guides clients in exploring the world-of-work. There are various ways to get into the career world, for example, clients could use integrated career assessment tool such as Discover to explore the recommended job clusters and occupational fields, or, clients could browse O-Net to understand the requirements and characteristics of the jobs. Finally, counselor introduces the CIP pyramid model to clients, and in addition to the first and second step as the knowledge domains of the pyramid model; counselor trains clients to adopt a systematic decision-making modelCASVE for better information processing and decision-making. Clients encountering career indecision are normally motivated to engaging in the career exploration activities, and by adopting CIP and pyramid model, clients are equipped with necessary knowledge and tools to make informed decision-making.

Similarly, based on the foundational principles of the CIP approach, McLennan and Arthur (1999) proposed an expanded framework to address the career 
problems solving and decision making for counseling with women, which is a sequential process that involves a seven-step sequence for interventions: initial interview, preliminary assessment, problem definition, goal formulation, individual learning plan development and execution, and follow-up with clients. McLennan and Arthur (1999) also provided a program evaluation of the modified CIP framework for career problem solving and decision-making. In their evaluation, McLennan and Arthur (1999) argued that there are two underpinnings to make a sound program evaluation. First of all, the program must have a theoretical framework, it is based on the most recent literature, and it must also have clear relevance to the specific needs of the targeted population. Secondly, the program must have measurable objectives in order to determine the effectiveness. Shoffner (2006) highly appraised that CIP is an excellent approach to use with clients who are interested in and motivated in linear decision-making. The pyramid of information processing domains and the CASVE linear decision-making model provides a solid theoretical framework. Furthermore, the application of CIP model attends to the measurable objectives. The two main objectives as outlined in McLennan and Arthur's (1999) evaluation are 1) teaching clients skills for identifying and coping with barriers to optimal career decision-making and 2) to design and implement action plans jointly formulated by both client and counselor. The both two objectives are measurable. The former objective can be met by observing client's demonstration of decision-making skills, interviewing skills, and assertive skills. The latter can be measured by the progress of the completeness of the individual learning plan as a supplement learning material from the CIP model (Peterson et al., 1991).

\subsection{A Case in Point}

Reardon and Wright (1999) illustrated a career counseling case by applying the CIP approach to a 19-year-old college student, Mandy. In this case, Mandy, a second semester sophomore enrolled in a career development course for academic credits. Mandy had not declared a major by the time, and she described herself as "undecided" for her first choice occupation. Mandy perceived herself being successful with whatever occupations she decided upon, but she generally lacked skills and means to make a quality and satisfying decision. Therefore, Mandy was motivated to attend the career development course and was positive about the intervention.

The counselor chose to utilize CIP approach to help Mandy with her decision-making process. The intervention was structured in three phases. During the first phase, counselor did an initial intake process with Mandy, gathering personal information and understanding Mandy's situation in terms of career decision-making. During the second phase, the counselor administered Holland Self-Directed-Search (Holland, 1970) to identify Mandy's salient occupational interests and Career Thoughts Inventory (CTI; Sampson Jr., Peterson, Lenz, Reardon, \& Saunders, 1996a) to address Mandy's thoughts around decision-making. 
During the third phase, built on the assessment results, counselor implemented a career development course based on CIP approach.

Mandy was also invited to write down an individual learning plan with the counselor. By the end of the career development course, Mandy was able to declare her major in Elementary Education. Most importantly, Mandy had a very clear picture about her personal traits and suitable occupational alternatives. Mandy was very excited and happy about the outcome of the intervention. This case demonstrated the applicability of the CIP approach to college students in career decision-making.

\section{Monitoring and Controlling Metacognitive Functions}

A major component of the CIP approach is the executive processing domain of the pyramid of information processing domains, which includes metacognitions. Sampson Jr., Peterson, Lenz, Reardon, and Saunders (1996b) defined metacognitions as the cognitive functions that control the selection and sequencing of cognitive strategies used to solve a career problem through self-talk, self-awareness, and control and monitoring. Sampson Jr. et al. (1996b) further defined that self-talk is the silent conversation people have with themselves concerning how well they are completing a given task; self-awareness is the extent to which people are aware of the nature and the impact of self-talk on their behaviors; and control and monitoring is the extent to which people is able to evaluate the quality and soundness of the self-talk. Negative career thoughts are low quality self-talk that might impede the career decision-making process. The ability to control and monitor cognitive functions is essential in identifying and altering those thoughts to be more appropriate and positive. In the following sections, an assessment designed to measure the level of dysfunctional thoughts will be firstly introduced. A review of relevant research literatures will then be introduced to reveal the relationship between negative thoughts and career decision-making; finally, the author will summarize researches of the effect of CIP approach to alter negative thoughts so as to improve the career decision-making quality.

\subsection{Career Thoughts Inventory (CTI)}

CTI was designed within the theoretical context of CIP model, and it targets to measure clients' mental readiness or dysfunction during the career decision-making process (Sampson Jr. et al., 1996a; as cited in Capuzzi \& Stauffer, 2006). This 48 -item assessment is a practical application to address clients' meta-cognitions, especially dysfunctional thoughts and beliefs that impede the development of career decisiveness. Sampson Jr. et al. (1996a) (as cited in Capuzzi \& Stauffer, 2006) theorized these dysfunctional thoughts and beliefs in the CTI as three categories: Decision Making Confusion (DMC), Commitment Anxiety (CA), and External Conflict (EC). The 14-item DMC subscale reflects an inability to initiate and sustain the decision-making process as a result of disabling emotions and/or lack of a general understanding of the decision-making process. 
The 10-item CA subscale reflects an inability to commit to a specific course of actions as a result of the decision-making process, accompanied with generalized anxiety. The 5-item EC subscale reflects an inability to balance the importance of self-perceptions with the importance of input from the significant others. CTI is widely used for service deliveries and researches. Researches have also demonstrated acceptable reliability and validity of the CTI in measuring dysfunctional career thoughts for high school students, college students, and adults (Sampson Jr. et al., 1996b).

\subsection{Relationship between Negative Thoughts and Career Decision-Making}

Numerous researches have found significant relationship between negative career thoughts and career decision-making. In general, it was found that negative career thoughts would impede the career decision-making process. For instance, Chason, Bullock-Yowell, Sampson, Lenz, and Reardon (2013) conducted a research to understand the relationships among career thoughts, career interests, and career decision state. In their research, 226 undergraduate students enrolled in a career course participated the study. Students completed Career Thoughts Inventory (CTI), Holland Self-Directed Search (SDS), and Occupational Alternatives Question (OAQ). The result suggests that there was no significant relationship between the SDS profile elevation and any of the subscales of the CTI; there were significant relationships between SDS profile differentiation and Commitment Anxiety, as well as differentiation and External Control. Furthermore, the result revealed significant relationships between career decidedness and Decision Making Confusion, and career decidedness and Commitment Anxiety. In general, the research team found that there was significant relationship between negative career thoughts and career decidedness and career satisfaction.

Saunders, Peterson, Sampson Jr., and Reardon (2000) also attempted to study the relationship between dysfunctional career thoughts and career indecision, but their study was complicated by another construct-depression. The researchers hypothesized that both affective and cognitive components contributed to the state of career indecision. In their research design, 215 undergraduate students enrolled in an introductory psychology course at a large southeastern university participated the research. Because previous researches had already find vocational identity, state anxiety, trait anxiety, and locus of control to be correlated with career indecision, these variances were controlled in this study. The researchers administered both CTI and Beck Depression Inventory (BDI; Beck, Ward, Mendelson, Mock, \& Erbaugh, 1979) to measure participants' level of career dysfunctional thoughts and depression. The researchers also administered Career Decision Scale (CDS; Osipow, Carney, Winer, Yanico, \& Koschir, 1976) to understand participants' level of career indecision. The result revealed that vocational identity, state anxiety, trait anxiety, locus of control, depression and dysfunctional career thoughts were all significantly related with career indecision; however, while vocational identity, state anxiety, trait anxiety, 
locus of control were controlled, only dysfunctional career thoughts was found to be significantly associated with career indecision. The affective nature of career indecision was somewhat less clear. Based on these findings, Saunders et al. (2000) proposed three recommendations for career service providers. Firstly, career professionals were again advised to utilize various interventions and tools to help clients develop vocational identities such as interests, skills, competences, and occupational knowledge. Secondly, since career indecision is a complex state, career professionals were advised to attend to signs and symptoms of depression before addressing career decision problems. Thirdly, career professionals are cautioned to look for thinking that inhibits one's ability to rationally approach career decision-making. Interventions thus needed to help clients' identity, alter, and replace dysfunctional career thoughts with more positive and proactive ones.

Several other researchers attempted to investigate the relationship between career and life stresses and career decision state. For example, Bullock-Yowell, Peterson, Reardon, Leierer, and Reed (2011) used a sample of 232 college students to study the relationship among career and life stresses, negative thoughts, and career decision state. This study revealed that an increase in career and life stress was associated with an increase in negative thoughts and an increase in such thoughts was associated with less career decidedness and satisfaction. However, when the variation associated the negative thoughts were accounted for, career and life stress and career decision were found to be inversely related, which is to say that the higher the career and life stress is the lower the career indecision and dissatisfaction. Bullock-Yowell et al. (2011) suggested that career professionals to be attentive to how negative thoughts would impede the career decision-making when individuals are encountering career and life stresses. In Strauser, Lustig, Cogdal, and Uruk's (2006) research, the researchers used a sample of 131 college students to study how traumatic experience would influence individuals' development of work personality. In their study, the work personality involves 1) a set of work behaviors such as attention to timeline, interaction with peers in workplaces, and appropriate on-task behaviors; 2) knowledge of self such as interests, skills, and values; and 3) ability to make effective career decisions. Trauma was termed as an experience that would cause individuals to encounter injury or death and provoke extensive feelings of terror and hopelessness. The results showed that there is significant relationship between high levels of trauma symptoms and high levels of negative career thoughts and low levels of work personality. The researchers interpreted that trauma symptoms may negatively affect individual's cognitive information processing, and the deficient in reasoning will then in turn negatively affect individuals' career decision-making quality. Similarly, Strauser et al. (2006) advised career professionals to be knowledgeable about PTSD and other trauma symptoms. Before addressing any other career issues, career professionals are advised to make referrals of clients exhibiting trauma symptoms or to teach individuals with better coping skills in the first place. 


\subsection{Applying CIP Approach in Overcoming Negative Thoughts}

Individuals hold negative thoughts or dysfunctional beliefs about career decision-making are termed as indecisive clients (Gati et al., 2011). Indecisive clients are normally suffering from pervasive and chronic difficulties. They may have pessimistic views toward career decision-making, may feel anxiety about the uncertainty, and may question their self-concept and identity thus resulting in low self-efficacy (Gati et al., 2011). The key intervention in applying the CIP approach with career indecisive clients would be to work with them primarily in the executive processing domain, which includes "self-talk, self-awareness, and the monitoring and control of cognitions" (Niles \& Bowlsbey, 2009: p. 95). Using CTI and CTI Workbook can help determine clients' readiness for career decision-making, identify clients' possible negative thoughts about career decision-making, reframe and consequently alter these negative thoughts. In real life practice, career professionals work according to the Pyramid Structure of the CIP model. First of all, career counselors engage in students with self-explorations and provisions of world-of-work information; secondly, career counselors apply structured career decision-making process to guide students through the CASVE (Communication, analysis, synthesis, value, and evaluation) model. CTI can be used before the second step, and its results can be interpreted during the decision-making process as an aid to address unrealistic and dysfunctional beliefs and thoughts.

Some researchers have demonstrated the effect of combining CIP-based career development courses to help college students in improving decision-making quality. Reed, Reardon, Lenz, and Leierer (2001) are among the first pioneers to bridge the gap between theory and practice. Reed et al. (2001) designed a 3 -credit-hour undergraduate career course to study its impact on participating students' dysfunctional career thinking. The career course was based on the CIP theory and used CTI as the primary instrument to study the effect of the course. Pre-test and post-test of CTI were administered, and the result showed that the students who participated career course significantly reduced their negative career thoughts. Furthermore, students who exhibited highest level of negative career thoughts before the course showed greatest gain. Ethnicity and sex were not found to be associated with the results. Similarly, Osborn, Howard, and Leierer (2007) wanted to know how a 6-week 1-credit-hour career course's effect in reducing negative career thoughts. They used a sample of 158 racially and ethnically diverse college freshmen and found that the participants significantly reduced their dysfunctional career thoughts after the course. Echoing Reed et al.'s (2001) finding, the reduction in dysfunctional career thoughts did not show relationship with either gender or race/ethnicity. These researches seem to prove that by using the CTI scores as a springboard to discuss college students' career decision-making challenges, students decreased the level of dysfunctional career thoughts, and thus improved their career decision-making quality. 


\section{Conclusion}

Osborn and Baggerly (2004) utilized a sample of 1280 (representing a 53\% response rate) public school counselors from the State of Florida to analyze school counselors' perception of career counseling and career testing preferences, priorities, and predictors. Their research result also demonstrated that the CIP theory was one of the two most preferred career intervention approaches. The other theory is the traditional trait-and-factory. The world is undergoing some major technology changes in the past five years especially in the field of quantum theory, gene-editing, and artificial intelligence. The world of career is becoming more and more unpredictable, so recommendations of occupations and career direction are seen not comprehensive or complete. Therefore, inspiring clients' own decision-making and challenging clients' thinking process by using CIP theory seem to be more promising.

However, it would be necessary for the founders of the theory to revisit the theoretical bases and the applicability of the CTI because the revision has not been done since 1996. In addition, the norm sample of CTI assessment is limited in the US thus the application to elsewhere is not solid. Nevertheless, the CIP theory incorporates the traditional trait-and-factor approach and the latest advancements in the field of human cognitive functions, and it has demonstrated its effect in helping college students in North America with quality career decision-making through a numerous empirical researches.

\section{Conflicts of Interest}

The authors declare no conflicts of interest regarding the publication of this paper.

\section{References}

Beck, A. T., Ward, C. H., Mendelson, M., Mock, J., \& Erbaugh, J. (1979). Beck Depression Inventory. Palo Alto, CA: Psychological Corporation.

Beggs, J., Bantham, J. H., \& Taylor, S. (2008). Distinguishing the Factors Influencing College Students' Choice of Major. College Student Journal, 42, 381-394.

Bullock-Yowell, E., Peterson, G. W., Reardon, R. C., Leierer, S. J., \& Reed, C. A. (2011). Relationships among Career and Life Stress, Negative Career Thoughts, and Career Decision State: A Cognitive Information Processing Perspective. The Career Development Quarterly, 59, 302-314. https://doi.org/10.1002/j.2161-0045.2011.tb00071.x

Capuzzi, D., \& Stauffer, M. D. (2006). Career Counseling: Foundations, Perspectives, and Applications. Boston, MA: Pearson Education.

Chason, A. K., Bullock-Yowell, A., Sampson, J. P., Lenz, J. G., \& Reardon, R. C. (2013). Relationships among Career Thoughts, Career Interests, and Career Decision State. The Canadian Journal of Career Development, 12, 39-47.

Gati, I., Gadassi, R., Saka, N., Hadadi, Y., Ansenberg, N., Friedmann, R., \& Asulin-Peretz, L. (2011). Emotional and Personality-Related Aspects of Career Decision-Making Difficulties: Facets of Career Indecisiveness. Journal of Career Assessment, 19, 3-20. https://doi.org/10.1177/1069072710382525 
Holland, J. L. (1970). The Self-Directed Search for Career Planning. Palo Alto, GA: Consulting Psychologists Press.

McLennan, N. A., \& Arthur, N. (1999). Applying the Cognitive Information Processing Approach to Career Problem Solving and Decision Making to Women's Career Development. Journal of Employment Counseling, 36, 82-96. https://doi.org/10.1002/j.2161-1920.1999.tb01011.x

Niles, S. G., \& Bowlsbey, J. H. (2009). Career Development Interventions in the 21st Century(3rd ed.). Upper Saddle River, NJ: Pearson.

Osborn, D. S., \& Baggerly, J. N. (2004). School Counselors' Perceptions of Career Counseling and Career Testing: Preferences, Priorities, and Predictors. Journal of Career Development, 31, 45-59. https://doi.org/10.1023/B:JOCD.0000036705.02911.df

Osborn, D. S., Howard, D. K., \& Leierer, S. J. (2007). The Effect of a Career Development Course on the Dyfunctional Career Thoughts of Racially and Ethnically Diverse College Freshmen. The Career Development Quarterly, 55, 365-377. https://doi.org/10.1002/j.2161-0045.2007.tb00091.x

Osipow, S. H., Carney, C. G., Winer, J. L., Yanico, B., \& Koschier, M. (1976). The Career Decision Scale (3rd ed.). Odessa, FL: Psychological Assessment Resources.

Peterson, G. W., Sampson, J. P., \& Reardon, R. C. (1991). Career Development and Services: A Cognitive Approach. Pacific Grove, CA: Brooks/Cole.

Peterson, G. W., Sampson Jr., J. P., Lenz, J. G., \& Reardon, R. C. (2002). A Cognitive Information Processing Approach to Career Problem Solving and Decision Making. In D. Brown, L. Brooks, \& Associates (Eds.), Career Choice and Development (4th ed.) San Francisco, CA: Jossey-Bass.

Peterson, G. W., Sampson, J. P., Reardon, R. C., \& Lenz, J. G. (1996). A Cognitive Information Processing Approach. In D. Brown, L. Brooks, \& Associates (Eds.), Career Choice and Development (3rd ed.). San Francisco, CA: Jossey-Bass.

Reardon, R. C., \& Wright, L. K. (1999). The Case of Mandy: Applying Holland's Theory and Cognitive Information Processing Theory. The Career Development Quarterly, 47, 195-203. https://doi.org/10.1002/j.2161-0045.1999.tb00730.x

Reed, C. A., Reardon, R. C., Lenz, J. G., \& Leierer, S. J. (2001). A Cognitive Career Course: From Theory to Practice. The Career Development Quarterly, 50, 158-167. https://doi.org/10.1002/j.2161-0045.2001.tb00980.x

Sampson Jr., J. P., Peterson, G. W., Lenz, J. G., \& Reardon, R. C. (1992). A Cognitive Approach to Career Services: Translating Concepts into Practice. Career Development Quarterly, 41, 67-74. https://doi.org/10.1002/j.2161-0045.1992.tb00360.x

Sampson Jr., J. P., Peterson, G. W., Lenz, J. G., Reardon, R. C., \& Saunders, D. E. (1996a). Career Thoughts Inventory (CTI). Odessa, FL: Psychological Assessment Resources.

Sampson Jr., J. P., Peterson, G. W., Lenz, J. G., Reardon, R. C., \& Saunders, D. E. (1996b). Career Thoughts Inventory Professional Manual. Odessa, FL: Psychological Assessment Resources.

Sampson Jr., J. P., Reardon, R. C., Peterson, G. W., \& Lenz, J. G. (2004). Career Counseling and Services: A Cognitive Information Processing Approach. Pacific Grove, CA: Brooks/Cole.

Saunders, D. E., Peterson, G. W., Sampson Jr., J. P., \& Reardon, R. C. (2000). Relation of Depression and Dysfunctional Career Thinking to Career Indecision. Journal of Vocational Behavior, 56, 288-298. https://doi.org/10.1006/jvbe.1999.1715

Shoffner, M. (2006). Career Counseling: Theoretical Perspectives. In D. Capuzzi, \& M. D. Stauffer (Eds.), Career Counseling: Foundations, Perspectives, and Applications (cus- 
tom ed., pp. 178-203). New York: Laureate Education Inc.

Strauser, D. R., Lustig, D. C., Cogdal, P. A., \& Uruk, A. (2006). Trauma Symptoms: Relationship with Career Thoughts, Vocational Identity, and Developmental Work Personality. The Career Development Quarterly, 54, 346-360.

https://doi.org/10.1002/j.2161-0045.2006.tb00199.x

Whitmarsh, L., Brown, D., Cooper, J., Hawkins-Rodgers, Y., \& Wentworth, D. (2007). Choices and Challenges: A Qualitative Exploration of Professional Women's Career Patterns. The Career Development Quarterly, 55, 225-236.

https://doi.org/10.1002/j.2161-0045.2007.tb00079.x 